\title{
PRIVATE EQUITY IN EMERGING MARKETS
}

\author{
Alexander Peter Groh
}


The CIIF, International Center for Financial Research, is an interdisciplinary center with an international outlook and a focus on teaching and research in finance. It was created at the beginning of 1992 to channel the financial research interests of a multidisciplinary group of professors at IESE Business School and has established itself as a nucleus of study within the School's activities.

Ten years on, our chief objectives remain the same:

- Find answers to the questions that confront the owners and managers of finance companies and the financial directors of all kinds of companies in the performance of their duties

- Develop new tools for financial management

- Study in depth the changes that occur in the market and their effects on the financial dimension of business activity

All of these activities are programmed and carried out with the support of our sponsoring companies. Apart from providing vital financial assistance, our sponsors also help to define the Center's research projects, ensuring their practical relevance.

The companies in question, to which we reiterate our thanks, are:

Aena, A.T. Kearney, Caja Madrid, Fundación Ramón Areces, Grupo Endesa, Royal Bank of Scotland and Unión Fenosa.

http://www.iese.edu/ciif/ 



\title{
PRIVATE EQUITY IN EMERGING MARKETS
}

\author{
Alexander Peter Groh ${ }^{1}$
}

\section{Abstract}

Why is there such a strong Private Equity market in the United States or the United Kingdom, why is activity relatively low in several other economically important countries, and why is it zero or close to zero in many emerging regions? Spatial variations of Private Equity activity result from numerous factors. In this paper, I summarize the literature contributions on the determinants of national Private Equity activity and comment on the consequences for the development of the asset class in emerging markets.

JEL Codes: G24, 016, R12

Keywords: Private Equity, Emerging Markets.

${ }^{1}$ Visiting Professor, Finance, IESE and GSMC - Montpellier Business School 


\section{PRIVATE EQUITY IN EMERGING MARKETS}

\section{Introduction}

Hellmann and Puri (2000), and Kortum and Lerner (2000) show that Private Equity (PE)-backed companies are more efficient innovators. Belke et al. (2003), and Fehn and Fuchs (2003) prove that they create more employment and growth than their peers. Levine (1997) documents well the role of PE funds in fostering innovative and competitive firms, and indeed, there now exists a broad consensus that a strong PE market is a cornerstone for commercialization and innovation in modern economies. What is valid for industrial countries should be even more important for emerging markets. The urgent need for capital especially for financing all kinds of infrastructure and communication in emerging regions is evident. The growth potential is enormous and deserves capital to be exploited. This capital can be provided by financial institutions that specialize in risk capital investments in small - to medium-size or young firms. Hence, policymakers should focus on the creation of an adequate setting for a prospering PE market to support investments, growth, competitiveness, and entrepreneurial activities, especially in emerging countries. However, the risk capital supply is rather small in emerging countries, even if institutional investors are increasingly looking internationally for new investment opportunities. One would expect emerging regions to attract PE investors due to the assumed economic growth rates, and the proportionate need for financing, especially for non-quoted corporations.

So why is there such a strong market for Private Equity in the United States, or the United Kingdom, and why is activity zero or close to zero in many emerging countries? Spatial variations in PE activity result from numerous factors. Partly, they can be explained by built-in bias mechanisms. The whole investment process from institutional investors (the Limited Partners or LPs) to the finally-backed corporations is geographically biased: the largest, most prominent and most active institutional investors in the PE asset class are located in the United States. This certainly contributes to the dominant role of the United States Private Equity market. However, and not only in the United States, institutional investors allocate their capital via chains of agents and networks in certain regions, and among countries. These allocations follow, in principle, a simple rationale: First, there is a professional community required to support transactions and to establish the capital supply side. Second, there must be expectation for demand of the committed capital.

The last elements along the chain of agents are the Private Equity funds (the General Partners or GPs). They prefer spatial proximity in their investments to facilitate the transaction processes, monitoring and active involvement. It is popular for GPs to focus on a particular region, or just 
on one single country when searching for deal opportunities. Hence, the geographical source of PE is generally not very distant from the demand. This built-in bias mechanism is intensified by the institutional investors' international allocation approaches. Diversification needs urge the LPs to commit capital to funds that cover a particular country or region. Therefore, LPs make a geographical selection of promising spots. The selection follows in principle their expectation of the demand for PE, and their evaluation of the host country's professional finance community. However, both the expected demand for PE and the state of a host country's professional environment depend likewise on many individual criteria which will be discussed later.

First I will give a brief overview over the world-wide PE activity, focusing on the emerging regions. Then I discuss literature on the determinants of spatial differences in PE markets. Next, I will present a survey among institutional investors that deals with their concerns when investing in emerging PE markets. This survey allows the subsequent comparison of emerging regions regarding their attractiveness for PE investments. Finally, I will comment on the most important allocation criteria, and conclude with some recommendations for emerging countries to attract more risk capital.

\section{International Comparison}

Figure 1 presents the volume of investments in the year 2007 for all countries of the world with some Private Equity activity. The data is provided by Thomson Financial. The left abscissa represents the amount in United States \$ invested by Private Equity funds in the particular countries. The axis is logarithmic scaled to allow for presentation of the different levels of investment activity. For example, the activity in the United States was about $\$ 116.5$ billion, while it was only $\$ 1.88$ million in Egypt. On the right axis, the activity is related to the size of the economies measured by their GDP.

\section{Figure 1}

World-Wide Comparison of Private Equity Activity

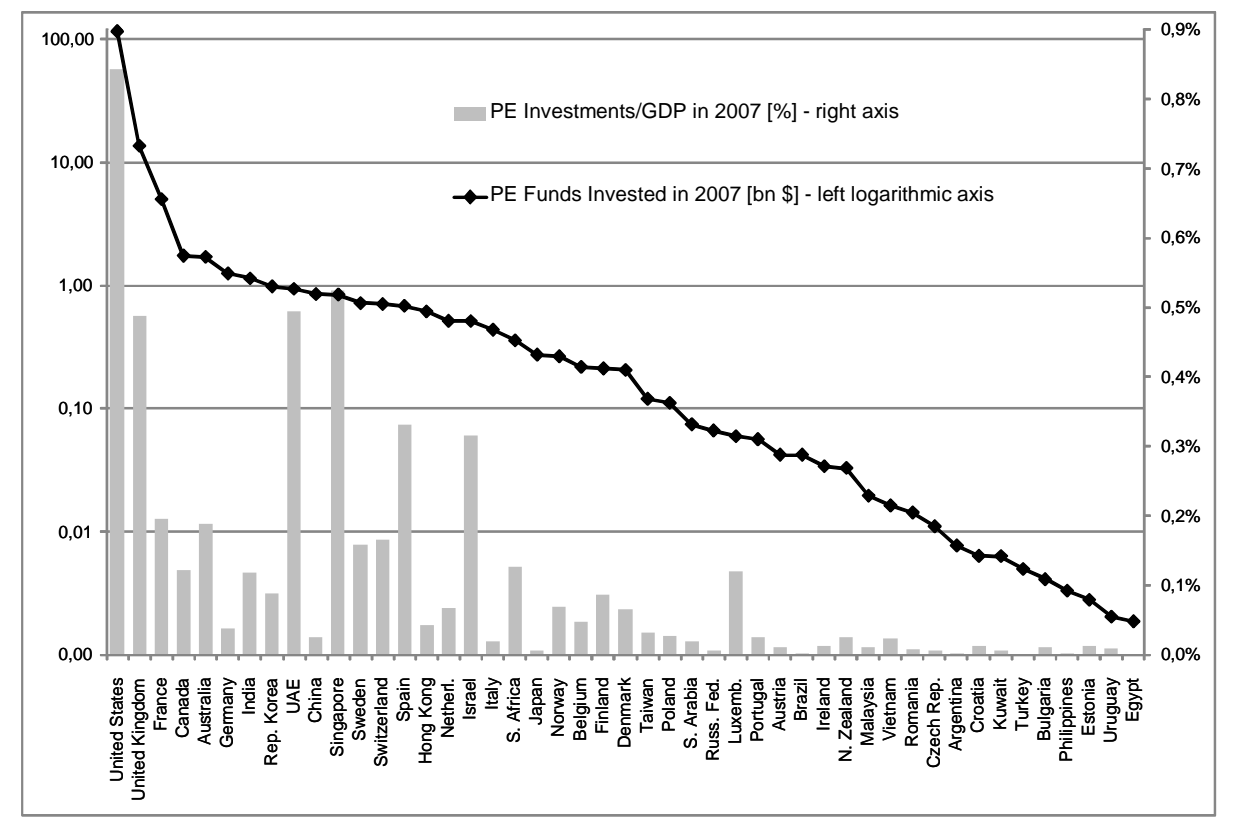

The Figure compares the Private Equity activity in all countries of the world. The data source is Thomson Financial. On the left logarithmic axis we find the volume in billion United States \$ of funds invested in the particular countries. The right axis presents the national activities related to the size of the economies measured in terms of the GDP. 
The Figure shows the dominant role of the United States and the United Kingdom in the worldwide PE market. However, it also reveals that, related to the economic size of the countries, there are some other PE 'hot spots', namely the United Arab Emirates, Singapore, Hong Kong, and Israel. Additionally, the Figure highlights that major economies, such as Germany and Japan, have rather low PE activity levels. Additionally, some emerging markets like India, China, South Africa, Malaysia, Vietnam, and Croatia, among others, have more activity in relation to their economic power than Japan, and some of them also have more than Germany.

This comparison raises the question for the determinants of the different levels of activity. The question is comprehensively discussed in literature on the requirements of vibrant Private Equity markets, and this is presented next.

\section{What Determines Emerging Market pe Activity?}

A large body of research explores the determinants of Private Equity markets in particular economies. Some of the papers focus on emerging regions, some of them on already established markets. Black and Gilson (1998), and Michelacci and Suarez (2004) highlight the important role of the stock market for the asset class. Kaplan and Schoar (2005) confirm the strong relation between PE activity and stock market waves. Jeng and Wells (2000) explore the determinants of risk capital funding for 21 countries and expand the work of Black and Gilson (1998). They show that IPOs are the strongest driving force of PE investing. Surprisingly, GDP growth and market capitalization are not significant. Gompers and Lerner (2000) emphasize that risk capital flourishes in countries with deep and liquid stock markets.

The availability of debt financing is a key factor for start-ups entering the market, as emphasized by Greene (1998), and hence a determinant for a vibrant, local PE market. Additionally, the maturity of the PE market itself might attract investors. The maturity of a local PE market is reflected by the number of players and supporting institutions, such as law firms, investment banks, M\&A boutiques, auditors and consultants. The supporting institutions are important to creating deal flow and exit transactions. Balboa and Martí (2003) find that annual fundraising volume is dependent on the previous year's market liquidity. If investors have confidence in the efficiency of a local PE market with an established track record, they continue investing in follow-on funds. Sapienza et al. (1996) claim that investor confidence is determined by whether or not the PE market is accepted within a society, and the historical development of that market. Chemla (2005) argues that the management of PE funds is costly. Particular regions become attractive to investors only if the deal flow is large enough, and if transaction volumes and expected payoffs exceed a certain amount that allows the management fees to be covered. Hence, there is a simple relationship between the size of an economy and PE activity. If an economy is too small, it is simply not on the scope of internationally acting institutional investors and, hence, the sources of PE.

Gompers and Lerner (1998) examine the forces that affected independent PE fundraising in the United States. They conclude that regulatory changes affect pension funds and overall economic growth, while fund-specific performance and reputation affect fundraising. They point out that there are more attractive opportunities for entrepreneurs if the economy is large and growing. Wilken (1979) argues that economic development facilitates entrepreneurship, as it provides a greater accumulation of capital for investments. Romain and van Pottelsberghe de la Potterie (2004) find that PE activity is related to GDP growth. 
La Porta et al. (1997 and 1998) prove that the legal environment strongly determines the size and extent of a country's capital market and local firm's abilities to receive outside funding. Glaeser et al. (2001), and Djankov et al. (2003 and 2005) suggest that parties in common law-countries have greater ease in enforcing their rights from commercial contracts. Cumming and Johan (2007) highlight that the perceived importance of regulatory harmonization increases institutional investors' allocations to the asset class. Desai et al. (2006) investigate the influence of institutional settings in 33 European countries, in particular the issues of fairness and the protection of property rights, on the entry of enterprises into the markets. The number of new enterprises is a proxy for the demand for PE. Cumming et al. (2006) find that the quality of a country's legal system is much more directly connected to facilitating PE backed exits than the size of a country's stock market. Cumming et al. (2008) extend this, and show that cross-country differences in legality, including legal origin and accounting standards, have a significant impact on the governance of investments in the PE industry. Better laws facilitate deal screening and deal origination. They also facilitate investors' board representations and the use of desired types of securities. Lerner and Schoar (2004) analyze PE transaction structures in developing countries and find that the choice of securities is driven by the legal and economic circumstances of the nation and of the investing PE group. La Porta et al. (2002) find a lower cost of capital for companies in countries with better investor protection. Lerner and Schoar (2005) confirm these findings. Johnson et al. (1999) show that weak property rights limit the reinvestment of profits in start-up firms. Even so, Knack and Keefer (1995), Mauro (1995), and Svensson (1998) demonstrate that property rights significantly affect investments and economic growth.

Da Rin et al. (2005) argue that policymakers should consider a wide set of policies to improve emerging PE markets, rather than simply channeling funds into the segment. Armour and Cumming (2006) confirm this rationale and show that government programs often hinder rather than help the development of PE markets.

Gompers and Lerner (1998) stress that the capital gains tax rate influences PE activity. Bruce (2000 and 2002), and Cullen and Gordon (2002) show that taxes affect the entry and exit of businesses. It can be concluded that this should be mirrored in PE activity.

Rigid labor market policies might negatively affect the attractiveness of a PE market. Institutional investors could hesitate investing in countries with exaggerated labor market protection and immobility. Lazear (1990), and Blanchard (1997) discuss how protection of workers can reduce employment and growth. Black and Gilson (1998) show that variations in labor market restrictions correlate with PE activity.

Access to viable investments is probably another important factor for the attractiveness of a regional PE market. Megginson (2004) argues that R\&D culture, especially in universities or national laboratories, plays an important role in fostering a growing risk capital industry. Gompers and Lerner (1998) show that both industrial and academic R\&D expenditure is significantly correlated with PE activity. Schertler (2003) emphasizes that the number of employees in the R\&D field and the number of patents, as an approximation of the human capital endowment, have a positive and highly significant influence on PE activity. Furthermore, Romain and van Pottelsberghe de la Potterie (2004) find that the level of entrepreneurship interacts with the R\&D capital stock, technological opportunities, and the number of patents. Lee and Peterson (2000), and Baughn and Neupert (2003) argue that national cultures shape both individual orientation and environmental conditions, which lead to different levels of entrepreneurial activity in particular countries, and which should affect the level of acceptance of a risk capital culture. The acceptance of a risk capital culture in a society should be reflected in the funding activities of institutional investors. 
Several papers analyze the evolvement of PE, especially in transition countries. Farag et al. (2004) focus on the VC/PE markets in Hungary, the Czech Republic and Poland, and compare them with the German market. From a survey among 68 GPs in the transition countries, they find several factors that hinder the emerging markets in catching up and reaching the chosen benchmark. They conclude that one clear major obstacle is a lack of talented people to manage the PE backed enterprises, as the quality of management ranks highly as a reason for investment failure. This finding is also consistent with Bliss (1999), Karsai et al. (1998), and Chu and Hisrich (2001). Furthermore, debt financing remains limited, thus making it difficult to gain the desired returns by leveraging transactions. The authors suggest that legal and institutional improvements to protect lenders effectively can, therefore, lead to growth in the supply of risk capital. Johnson et al. (1999) emphasize the importance of the protection of property rights in emerging regions while they find access to bank financing does not present a problem. These findings are in line with Klonowski (2005), who defines 26 decision criteria for individual transactions in emerging economies, and identifies the most important ones through a survey among 200 GPs.

This literature overview presents the numerous papers and their results. However, the literature does not provide a clear conclusion which of the particular criteria is the most important, nor does it provide any ranking of the criteria. One of the major obstacles is that each paper focuses on a small selection of the named criteria only, and none of them includes a larger selection or all of them. The problem is the availability of data when analyzing these parameters on a cross national comparison. Hence, it is impossible to assess the competitive position of countries regarding the reception of risk capital funding, and this opens the discussion about the ranking of relevance of the mentioned determinants for institutional investors in their international allocation decision processes. Therefore, Groh and Liechtenstein (2009a) perform a survey among institutional investors to find out about the relevance of the discussed issues when allocating PE in emerging markets. Their findings are summarized in the subsequent section.

\section{Survey Among Institutional Investors on the Importance of Emerging Markets Allocation Criteria}

In their paper, Groh and Liechtenstein (2009a) describe a survey they conducted among internationally acting institutional investors in PE Limited Partnerships. They directly address the suppliers of PE, and not the managing GPs, and simply ask about the relevance of different allocation criteria when investing in emerging PE markets. This distinguishes their study from others, because other papers perform surveys among local GPs in a certain host country or determine relevant parameters indirectly via regressions. The survey comprehensively deals with socio-economic criteria that the respondent considers important for allocation decisions. The survey was addressed to 1,079 Limited Partners world-wide. The geographic distribution of the addressees is as follows: 77\% United States and Canada, 17\% Europe, 5\% Asia, and 1\% others. The email addresses of the Limited Partners are collected from three commercial databases. Unfortunately, it is not known what the entire population of LPs is in terms of numbers and funds under management. A reliable or official list of institutional investors that qualify for PE partnerships does not exist. Each of the three databases claims to cover the whole population of LPs, but matching them leads to a larger number of players because some investors are missing from one or other database. Hence, Groh and Liechtenstein (2009a) gain a unique world-wide compendium of Limited Partners. Furthermore, they check several references and actively search for important and well-known LPs manually in their repository. They 
deliberately attempt to cover as many LPs as possible. Nevertheless, matching the databases and the cross-checks might not secure a valid collection of LPs that, at least, represents the entire population. Regarding the geographical distribution of investors, for example, they have the following concern: Even though the United States, as an economic region and as the best developed financial market, probably embodies the biggest (in terms of fund volumes), most sophisticated, and the largest number of LPs, other regions, notably Asia, might be underrepresented. However, in terms of funds under management, their data collection reliably represents the population. None of the larger LPs should be missing from their repository, be it in the United States, Europe or Asia, and the larger institutions are the more important ones because of their market weight. Groh and Liechtenstein (2009a) believe that an over-representation of the number of United States LPs in their repository of addresses will not harm the conclusions unless they respond in a different manner. However, they address this issue and investigate their sample with respect to differences in the allocation processes of sub-groups of the investors.

They received valuable responses from 75 investors - a response rate of 7\% and quite satisfying when compared to some other studies that collect primary data about investors' behavior by means of a questionnaire. For instance, Lerner and Schoar (2005) collect data from 28 Private Equity funds, and Köke (1999) considers a sample of only 21 responses.

The responding LPs are segmented into the following groups: corporate investors, government agencies, banks, pension funds, insurance companies, funds of funds, endowments, and others. A geographic distinction is made according to the origin of the investors: United States and Canada, Europe, and rest of the world. The segments are presented in Table 1.

\section{Table 1}

Types and Origins of Investors who Responded to the Groh and Liechtenstein (2009a) Survey

\begin{tabular}{|l|c|l|c|}
\hline Type of Investor & Occurrence & Origin of Investor & Occurrence \\
\hline Corporate Investors & 4 & United States and Canada & 34 \\
\hline Government Agency & 1 & Europe & 38 \\
\hline Banks & 3 & Rest of the World & 3 \\
\hline Pension Funds & 8 & & \\
\cline { 1 - 2 } Insurance Companies & 1 & & \\
\cline { 1 - 2 } Funds of Funds & 29 & & \\
\cline { 1 - 2 } Endowments & 2 & & \\
\cline { 1 - 2 } Others & 26 & & \\
\cline { 1 - 2 } Not Available & 1 &
\end{tabular}

The Table segments the responding investors according to their institutional type and according to their geographical origin.

Unfortunately, the response rate from LPs that qualify themselves as 'others' is relatively large and, therefore, only the 'funds of funds' group can be distinguished as homogeneous. Furthermore, Groh and Liechtenstein (2009a) received more answers from European LPs (49.3\% of all the answers), as compared to their occurrence in our depository of $17 \%$. This might bias the results of our study. Regardless, the geographical distribution might not be the only cause of a selection bias - investors' types, fund sizes, or other criteria might also not be sufficiently representative. Unfortunately, as mentioned above, since no comparable comprehensive repository of investor data exists that provides the necessary information to correct for a potential bias they are unable to address this issue. However, they separately assess the responses of sub-groups of investors, e.g., Europeans and non-Europeans, or small and large funds, and find out by mean comparison tests that there are no meaningful differences in their 
international capital allocation approaches. This leads them to conclude that, even if their sample does not perfectly represent the world-wide population of (potential) Limited Partners, the findings are not biased. The criteria are homogenous among the investors and, hence, their results are representative.

In their questionnaire, they consider the issues discussed in the literature overview, and group them into six main drivers for PE funding: Economic Activity, Capital Market, Taxation, Investor Protection \& Corporate Governance, Human \& Social Environment, and Entrepreneurial Opportunities. The respondents are asked to evaluate the importance of the individual criteria for their emerging market PE allocation decisions on a seven-point Likert scale, ranging from "not at all important" 1, to "very important" 7. To ensure that they do not miss any relevant determinant, they ask the respondents in parallel to determine their three most important allocation criteria using keywords. The analysis of these keywords reveals that no major topic is left out of their questionnaire. Figure 2 presents the six major categories, all individual criteria they asked for, the number of valid responses, their mean values, and the $+/$ - range of one standard deviation around the means. ${ }^{1}$

\section{Figure 2}

Nominations of Importance of Criteria when Investing in Emerging Markets

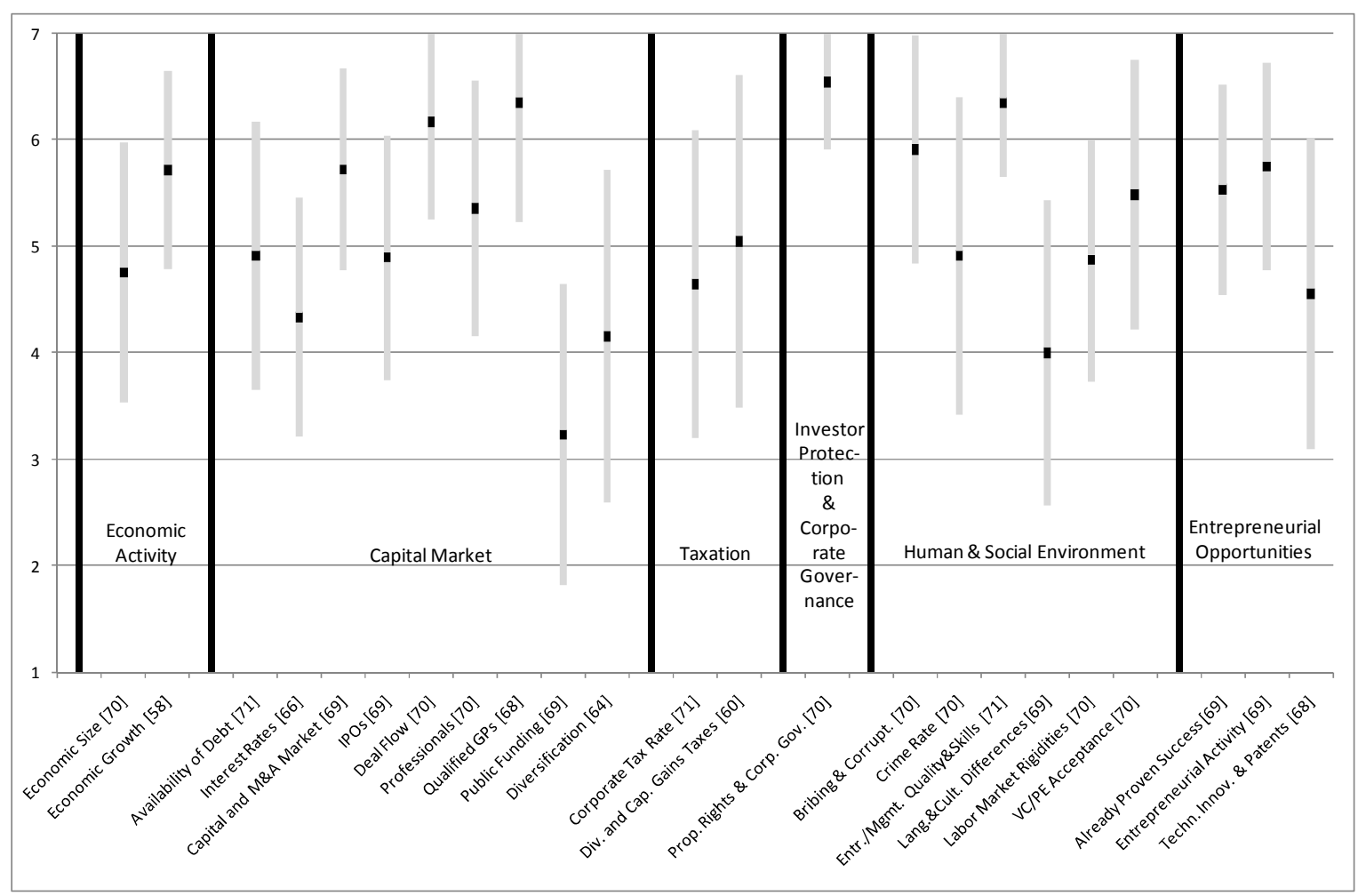

Source: Groh and Liechtenstein (2009b), Figure 1.

The Figure presents mean nominations on a seven point Likert scale and standard deviations of importance nominations of several criteria when deciding about PE emerging market allocations. The criteria are grouped into Economic Activity, Capital Market, Taxation, Investor Protection \& Corporate Governance, Human \& Social Environment, and Entrepreneurial Opportunities. The representation of the standard deviation is truncated for some nominations at the highest Likert score.

\footnotetext{
${ }^{1}$ Note: The ordinate is truncated at level 7 and, therefore, this limits the representation of the standard deviation in some cases.
} 
Figure 2 reveals that, on average, corporate governance principles and the protection of investors' rights is named as the most important criterion for Limited Partners' investment decisions in emerging markets, and that the availability of public subsidies is named as the least important of all of them. The figure allows several comments and many interpretations which are beyond of the scope of this chapter. However, it should be highlighted that public activity via subsidies or privileged credit conditions are obviously not adequate to increase PE funding from institutional investors. Private money does not follow public money; institutional investors are not impressed by government programs to spur risk capital markets. This finding is of particular importance for many (not only emerging) countries that attempt to increase local PE activity, and likewise confirms Da Rin et al. (2005) and Armour and Cummming (2006).

Figure 2 also presents that the relevance nominations are quite close to each other and have large standard deviations. Hence, it is still not clear which of the criteria has to be considered "the most important". Therefore, in a next step, Groh and Liechtenstein (2009a) focus on the first five criteria - the protection of property and investor's rights (with a mean nomination of 6.55 points), the presence of qualified GPs (6.35), the expected entrepreneurial management quality and skills (6.35), the expected deal flow (6.17), and bribing and corruption (5.91) - and try to determine a clear ranking of their relevance. Wilkoxon Signed Rank tests are adequate to determine this ranking. The non-parametric test considers the mean nominations and their standard deviations, and detects if the difference in the mean nominations of two paired criteria is statistically significant. The resulting rankings are presented in Table 2.

\section{Table 2}

The Five Most Important Criteria for LPs' International PE Allocation Decisions in Emerging Markets, Source: Groh and Liechtenstein (2009a), Table 8

\begin{tabular}{|l|c|}
\hline Criteria & Possible Ranks \\
\hline Protection of Property and Investor's Rights & 1 or 2 \\
\hline Presence of Qualified GPs & 1 or 2 or 3 or 4 \\
\hline Expected Entrepreneurial Management Quality and Skills & 2 or 3 or 4 \\
\hline Expected Deal Flow & 2 or 3 or 4 or 5 \\
\hline Bribing and Corruption & 4 or 5 \\
\hline
\end{tabular}

The Table names the five most important criteria and presents their possible ranks in the decision making process of institutional investors. The ranks are not exclusive as some of the criteria are tied.

The table reveals that the definition of absolute ranks is impossible on a 0.05 significance level. However, the protection of investors can either rank at the first or at the second position. It is not clear if it is ranked prior to the presence of qualified GPs, but it is certainly ranked ahead of the third criterion, the expected entrepreneurial management quality and skills. The investors' claims in the PE funds and, additionally, the claims of the PE funds in the target companies have to be secured. If institutional investors are not confident with that issue, they are reluctant to invest. As a result, issues relating to investor protection are the major obstacles for the development of emerging PE markets. This confirms the cited numerous literature contributions, and highlights the importance of the legal environment and the law enforcement possibilities in the emerging host countries. The finding will be discussed further below.

Nevertheless, the presence of qualified GPs also has a very high importance (possibly at rank 1 , 2, 3, or 4). This criterion is immediately followed by the expected entrepreneurial management quality and skills (which can rank at positions 2, 3, or 4, but not ahead of investor protection). Both criteria emphasize the role of talented people for the asset class, on the level of the 
managing PE fund as well as on the level of the backed corporations. Institutional investors have to rely on their agents. If they doubt their managerial capabilities, their loyalty, or their entrepreneurial culture and attitude, in short, if investors do not feel comfortable relying on people as the driving forces for PE business, they will not commit capital.

Following on, from the role of people, the expected deal flow materializes (possibly ranked at positions 2, 3, 4, or 5). This criterion is rather comprehensible, given that the asset class is return driven: Without having the expectation for good deal opportunities, any allocation is absurd. However, the characteristic of this criterion in a particular country depends on many different issues. On one hand, deal opportunities exist due to economic and entrepreneurial activity. Regarding emerging markets, that means in the first place that the local economy has to initiate deal flow. This requires a certain economic size which might not (yet) be present in many of the emerging countries. New corporations have to be founded, others have to be restructured, spun-off, streamlined, or positioned for growth. Without a body of already existing corporations, and without entrepreneurial culture and activity, these opportunities will not arise. On the other hand, the deal flow has to be "handled". This means that a supporting financial community has already been established in the emerging country. There have to be deal supporting institutions, such as M\&A Boutiques, Banks, Lawyers, Consultants, Accountants, and others. If they are not present, professional deal making is impossible. At the same time, one can imagine that all these determinants are inter-related. The supporting financial community will be established if there is proportionate economic activity. The degree of economic activity depends on the entrepreneurial culture and, likewise, on the protection of property rights. The legal protection results from the political and societal will for protection, and might be affected by education and the historical development of a country. Black and Gilson (1998) call it a chicken and egg problem: A market for risk capital requires legal protection and a financial community. The financial community requires entrepreneurs who deserve financial backing, sound economic conditions, and legal protection. This relates to, and strongly confirms the findings on the importance of property rights protection and law enforcement structures, such as La Porta et al. (1997 and 1998), Johnson et al. (1999), Glaeser et al. (2001), Djankov et al. (2003 and 2005), Lerner and Schoar (2004 and 2005), Desai et al. (2006), Cumming et al. (2006a and 2006b), and Cumming and Johan (2007). Roe (2003) contributes to that discussion, and comprehensively analyzes the legal systems of different countries, their historical and political development, and their impact on the national financial markets, the corporations and their ownership structure, and governance culture. He emphasizes the advantages in common law systems, but legal systems are historically determined and hardly changeable. However, regardless of their legal system, emerging countries should take into account the benefits provided by common law, and consider important aspects of property rights protection and corporate governance culture within their legislation.

Finally, institutional investors rank the importance of bribing and corruption as high (either at rank 4 or 5). This coincides with their desire for protection: Investors fear bribery and corruption as these directly interfere with the enforcement of their claims. As a result, investor protection, law enforcement possibilities and, hence, the quality of a legal system and its administrational efficiency, all affect investors' allocation decisions regarding many different aspects. Unfortunately, bribery and corruption remain a frequent problem (not only) in emerging regions. 
This relates to the question of how institutional investors assess that and the other discussed criteria in emerging markets. The following section deals with this issue.

\section{Perceptions of Particular Allocation Criteria in Emerging Markets}

Additional to the determination of the relevance of the PE allocation criteria, Groh and Liechtenstein (2009a) collect data on LPs' concerns when investing in emerging markets. The institutional investors named their appreciation of the criteria from Figure 2 in emerging regions. The criteria are grouped into the main drivers: Economic Environment, Capital Market, Social Environment, Investor Protection, Taxation, and Entrepreneurial Opportunities. The respondents rank the characteristics of the criteria in emerging markets on a seven-point Likert scale from not at all attractive $(=1)$ to very attractive $(=7)$. The results of the nominations and the number of responses are presented in Figure 3.

\section{Figure 3}

Appreciation of Allocation Criteria in Emerging Markets [Fluctuating Numbers of Responses]

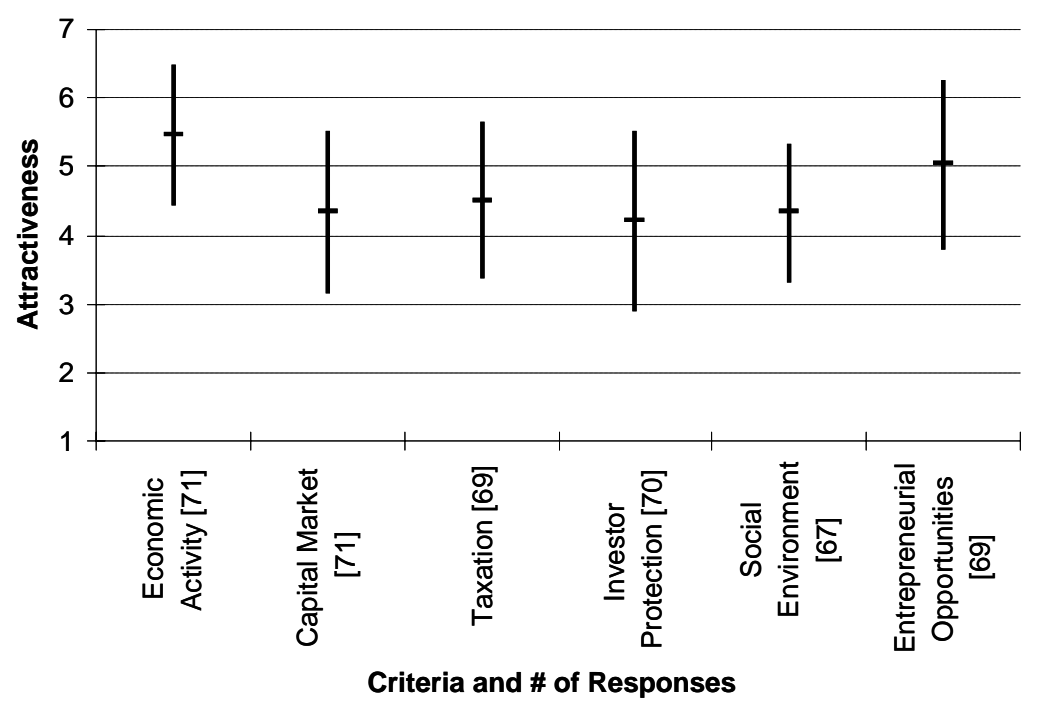

Source: Groh and Liechtenstein (2009a), Figure 10.

The Figure presents the nominations of appreciation of the six main emerging market allocation criteria Economic Activity, Capital Market, Taxation, Investor Protection, Social Environment, and Entrepreneurial Opportunities, their standard deviations, and the number of responses.

Figure 3 shows the mean nominations and the $\pm \sigma$-percentiles regarding investors' appreciation of the six key driving factors. Again, as no clear ranking across these factors is possible, Groh and Liechtenstein (2009a) repeat the Wilcoxon Signed Rank tests and receive the ranking result as shown in Table 3. 


\section{Table 3}

Appreciation of Key Driving Allocation Criteria in Emerging Markets

\begin{tabular}{|l|c|}
\hline Criteria & Rank(s) \\
\hline Economic Activity & 1 \\
\hline Entrepreneurial Opportunities & 2 \\
\hline Taxation & $3 / 4 / 5$ \\
\hline Capital Market & $3 / 4 / 5 / 6$ \\
\hline Social Environment & $4 / 5 / 6$ \\
\hline Investor Protection & $4 / 5 / 6$ \\
\hline
\end{tabular}

Source: Groh and Liechtenstein (2009a), Table 6.

The Table presents a ranking of the appreciation of the mains six allocation criteria Economic Activity, Entrepreneurial Opportunities, Taxation, Human \& Social Environment, and Investor Protection in emerging markets. While investors regard Economic Activity, and Entrepreneurial Opportunities in emerging regions as attractive, they are rather disappointed by the Social Environment and by their protection.

Figure 3 and Table 3 have to be interpreted with caution. It is clear that no emerging region is easily comparable to the others. Challenges for African countries are certainly different from challenges for Latin American or South East Asian emerging countries, not only with respect to economic development. However, the institutional investors' appreciations regarding emerging regions unfortunately reveal the opposite of what they consider important: The most important allocation criterion, namely, the protection of property rights, is ranked poorly for emerging regions. Hence, missing investor protection, and law enforcement capacities are obviously the strongest obstacles for PE investments in emerging markets. This is similar to the criteria ranked second and third in the order of importance: the presence of qualified GPs and the expected entrepreneurial management quality. Both criteria are affected by the social environment in emerging countries, and by their capital markets. The social environment and the capital markets receive low rankings in investors' appreciations of emerging regions. This is in line with the findings from Farag et al. (2004), Bliss (1999), Karsai et al. (1998), and Chu and Hisrich (2001) who stress the lack of talented and experienced people in emerging countries to develop a vibrant risk capital community. The lack of talented and experienced people refers to the management level of local GPs, the supporting institutions, and to the level of the PE-backed corporations. It further refers to the management abilities and experiences according to market-oriented and world-wide competitive standards.

On the other hand, investors appreciate the economic growth perspectives, and the resulting entrepreneurial opportunities in emerging regions. However, growth opportunities are not enough to attract the institutional capital; it is mandatory to meet the other requirements. Institutional investors refrain from investing if they miss a satisfying level of investor protection, entrepreneurial management skills, and capital market activity.

\section{Investors' Preferences Regarding Different Emerging Regions}

Emerging regions are in competition to attract funding from institutional investors. LPs might prefer certain regions due to the characteristics of the previously-discussed allocation criteria. Within their survey, Groh and Liechtenstein (2009a) analyze the institutional investors' preferences regarding the different emerging regions in the world, differentiating between Africa, Central Eastern Europe (CEE), China, The Commonwealth of Independent States - the former Soviet Union (CIS), India, Latin America, and South East Asia. The respondents specify their perceptions on a range from "not at all attractive" (1) to "very attractive" (7) on the seven- 
point Likert scale. The mean nominations, the $\pm \sigma$-percentile, and the number of responses for the different emerging regions are presented in Figure 4.

\section{Figure 4}

Attractiveness of Different Emerging Regions, [Fluctuating Numbers of Responses]

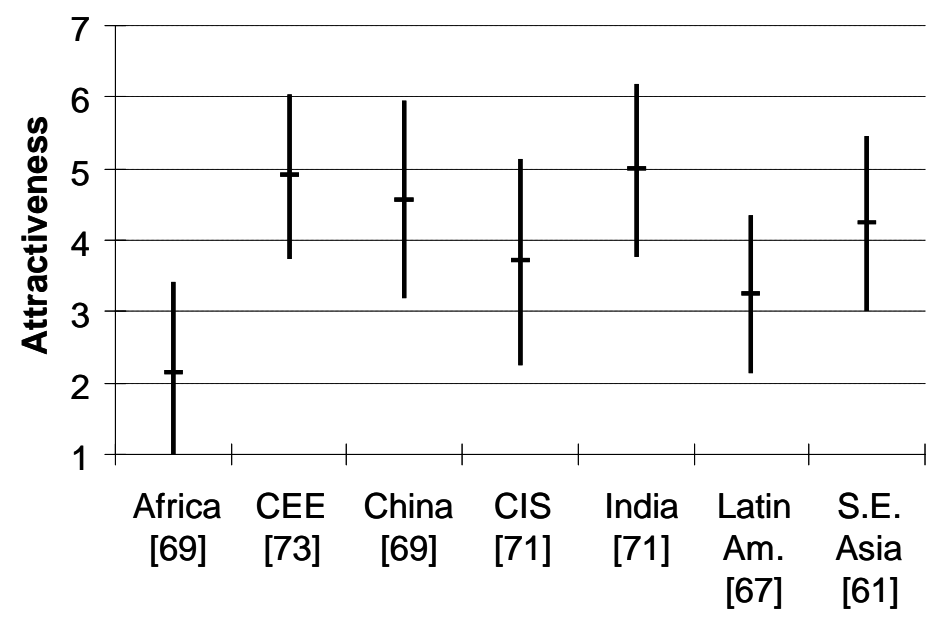

Regions and \# of Responses

Source: Groh and Liechtenstein (2009a), Figure 3.

The Figure presents the mean nominations of the appreciations of the different emerging regions Africa, Central Eastern Europe (CEE), China, The Commonwealth of Independent States - the former Soviet Union (CIS), India, Latin America, and South East Asia, their standard deviations, and the number of responses.

Figure 4 shows that India, Central Eastern Europe, and China are ranked top, followed by South East Asia, the Commonwealth of Independent States, and Latin America. Africa is ranked lowest. However, once again, the standard deviations of the nominations do not allow a clear order of preferences for the individual regions. Therefore, Groh and Liechtenstein (2009a) again perform Wilcoxon Signed Rank tests to obtain a clearer picture about the institutional investors' appreciations of the emerging economies. Unfortunately, the test results fail to provide a final ranking of the individual regions on a 0.05 significance level as some ranks are tied. Table 4 presents the possible ranks.

\section{Table 4}

Ranks of Attractiveness of Different Emerging Regions

\begin{tabular}{|l|c|}
\hline Region & Rank(s) \\
\hline India & $1 / 2$ \\
\hline CEE & $1 / 2 / 3$ \\
\hline China & $2 / 3 / 4$ \\
\hline South East Asia & $3 / 4$ \\
\hline CIS & 5 \\
\hline Latin America & 6 \\
\hline Africa & 7 \\
\hline
\end{tabular}

Source: Groh and Liechtenstein (2009a), Table 4.

The Table presents the ranking of institutional investors' appreciation of the different emerging regions India, Central Eastern Europe (CEE), China, South East Asia, The Commonwealth of Independent States - the former Soviet Union (CIS), Latin America, and Africa. 
According to Table 4, three tier groups can be identified: The first tier group consists of India (that can rank either at 1 or 2), the Central Eastern European countries (either at rank 1, 2 or 3), and China, while China might also form the second tier group (either at rank 2, 3 or 4 but not ahead of India), together with South East Asia (either at rank 3 or 4 but not ahead of CEE). The Commonwealth of Independent States, Latin America, and Africa belong to the third tier group in the mentioned order of preference.

These investors' expectations are hardly reflected in the pattern of PE activity in 2007, as presented in Figure 1. India leads the ranking of emerging market investment activity, closely followed by China. Adding up the investment volumes of all individual Central Eastern European countries yields a much lower activity than in China and, therefore, does not correspond to the ranking in Table 4. However, the other emerging regions follow with their PE activity according to the preferences in Table 4. Latin America and, notably, Africa are little appreciated by Limited Partners, and show very little PE activity only. Investments in Africa hardly exceeded \$360 million in 2007.

\section{Conclusions}

Emerging markets should be very attractive for risk capital investors. The urgent need for capital, especially for all kinds of infrastructure and communication financing, is evident, and the large expected growth opportunities over several years deserve capital to be exploited, preferably by small and medium sized non-quoted corporations. However, expected growth is not all that matters for investors in the PE asset class. There is a large variety of criteria that affect PE funding. Numerous contributions in literature deal with the success factors for vibrant risk capital markets. Investor protection and corporate governance are the dominant criteria named in literature, but many others are also considered important. Groh and Liechtenstein (2009a) run a survey among institutional investors in the asset class and find that the protection of property rights and corporate governance are indeed perceived as most important for international PE allocation decisions. The criterion is followed by the assessment of the management quality of local GPs and entrepreneurs according to Western management standards, by the expected deal flow, and by bribery and corruption. The availability of public funding and subsidiaries plays no role in allocation decisions. Institutional investors in PE are not impressed by government programs to spur local risk capital markets: public money will not attract private money.

The ranking of decision criteria reveals the investors' dependency on the subsequent chain of agents. Investors rely on the quality of the GPs they invest in. The GPs themselves rely on the managers of the corporations they finally back. If investors' claims are poorly protected, if they doubt the quality of their investees, or if they doubt integrity in a host country in general, then they refrain from investment.

Unfortunately, institutional investors poorly rank these exact characteristics in emerging regions. They are attracted by expected growth and the corresponding entrepreneurial opportunities. However, they are not satisfied with the protection of their claims, with the required resources and conditions to establish deal flow, and with the management experience of locals. Regarding different emerging regions, investors favor India, Central Eastern Europe, and China. They are less attracted by South East Asia, the Commonwealth of Independent States, Latin America, and Africa. 
What needs to be done to improve the emerging regions' ability to attract risk capital investors? If corporate governance and the protection of property rights are the most important criteria in the LPs' allocation process, host country politicians should take into account these concerns of institutional investors. Glaeser et al. (2001), and Djankov et al. (2003 and 2005) discuss the impact of law on finance, and La Porta et al. (1997 and 1998) confirm that the legal environment strongly determines the size and liquidity of a country's capital market. Roe (2006) expands this line of research and comments on the historical development of corporate governance rules for major economies. He points to the importance of shareholder protection for the establishment of a vibrant capital market. Cumming et al. (2008) show that differences in legality have significant impact on the governance of investees by PE funds. Cumming et al. (2006) comment on the quality of a legal system to facilitate PE-backed exits. Similarly, Black and Gilson (1998) emphasize the role of the professional infrastructure that accompanies stock market-centered capital markets to divest PE-backed corporations by IPOs. However, they also name it a "chicken and egg problem": a risk capital market requires a stock market with its finance professional community, but a stock market requires entrepreneurs and IPOs, which in turn, require a PE market. But instead of creating multiple new institutions, they recommend piggybacking on the institutional setting of another country. If this is successful, it will bring a potential for the development of local institutions. For example, corporations in emerging markets could piggyback on the already well-established financial communities and stock markets in the United States, Europe, or Asia. Additionally, foreign PE funds might find it profitable to hire and train locals in emerging countries to help them find good investment opportunities. Once trained, some of them will found their own companies locally, compete with their former employers, and, hence, establish a competitive risk capital market.

However, the discussion reflects the capital supply side only. One should also take into account that many emerging countries lack several other criteria to develop a vibrant PE market. Without sufficient entrepreneurial culture and entrepreneurial opportunities, with bureaucratic or societal burdens, or with bribery and corruption, there will be no demand for risk capital. If there is no demand, there is also no need to piggyback on any other country's institutions. 


\section{References}

Armour, J. and D. Cumming (2006), "The Legislative Road to Silicon Valley," Oxford Economic Papers 58, pp. 596-635.

Balboa, M. and J. Martí (2003), “An Integrative Approach to the Determinants of Private Equity Fundraising,” SSRN Working Paper 493344.

Baughn, C. C. and K. E. Neupert (2003), "Culture and National Conditions Facilitating Entrepreneurial Start-ups," Journal of International Entrepreneurship, 1, pp. 313-330.

Belke, A., R. Fehn, and N. Foster (2003), "Does Venture Capital Investment Spur Employment Growth?”, CESIFO Working Paper 930.

Black, B. and R. Gilson (1998), "Venture Capital and the Structure of Capital Markets: Banks versus Stock Markets,” Journal of Financial Economics, 47, pp. 243-277.

Blanchard, O. J. (1997), “The Medium Run,” Brookings Papers on Economic Activity, pp. 89-158.

Bliss, R. T. (1999), "A Venture Capital Model for Transitioning Economies: The Case of Poland," Venture Capital, 1, pp. 241-257.

Bruce, D. (2000), "Effects of the United States' Tax System on Transition into Selfemployment," Labor Economics, 7, pp. 545-574.

Bruce, D. (2002), "Taxes and Entrepreneurial Endurance: Evidence from the Self-employed," National Tax Journal, 55, pp. 5-24.

Chemla, G. (2005), "The Determinants of Investment in Private Equity and Venture Capital: Evidence from American and Canadian Pension Funds," SSRN Working Paper 556421.

Chu, P. and R. D. Hisrich (2001), "Venture Capital in an Economy in Transition," Venture Capital, 3, pp. 169-182.

Cullen, J. B. and R. H. Gordon (2002), "Taxes and Entrepreneurial Activity: Theory and Evidence for the U.S.," NBER Working Paper 9015.

Cumming, D., G. Flemming, and A. Schwienbacher (2006), "Legality and Venture Capital Exits," Journal of Corporate Finance, 12, pp. 214-245.

Cumming, D. and S. Johan (2007), "Regulatory Harmonization and the Development of Private Equity Markets," Journal of Banking and Finance, 31, pp. 3218-3250.

Cumming, D. D. Schmidt, and U. Walz (2008), "Legality and Venture Governance around the World," Journal of Business Venturing (forthcoming).

Da Rin, M., G. Nicodano, and A. Sembelli (2005), "Public Policy and the Creation of Active Venture Capital Markets," European Central Bank Working Paper 430.

Desai, M., P. Gompers, and J. Lerner (2006), "Institutions and Entrepreneurial Firm Dynamics: Evidence from Europe," Harvard NOM Research Paper 03-59. 
Djankov, S., R. La Porta, F. López-de-Silanes, and A. Shleifer (2003), “Courts," Quarterly Journal of Economics, 118, pp. 453-517.

Djankov, S., R. La Porta, F. López-de-Silanes, and A. Shleifer (2005), “The Law an Economics of Self-dealing," NBER Working Paper 11883.

Farag, H., U. Hommel, P. Witt, and M. Wright (2004), "Contracting, Monitoring, and Exiting Venture Investments in Transitioning Economies: A Comparative Analysis of Eastern European and German Markets," Venture Capital, 6,4, pp. 257-282.

Fehn, R. and T. Fuchs (2003), "Capital Market Institutions and Venture Capital: Do they Affect Unemployment and Labour Demand?," CESIFO Working Paper 898.

Glaeser, E. L., S. Johnson, and A. Shleifer (2001), “Coase vs. the Coasians," Quarterly Journal of Economics, 116, pp. 853-899.

Gompers, P. and J. Lerner (1998), “What Drives Venture Fundraising?," Brooking Papers on Economic Activity, Microeconomics, pp. 149-192.

Gompers, P. and J. Lerner (2000), "Money chasing deals? The Impact of Funds Inflows on the Valuation of Private Equity Investments,” Journal of Financial Economics, 55, pp. 281-325.

Greene, P. G. (1998), "Dimensions of Perceived Entrepreneurial Obstacles,” In P. Reynolds (ed.), "Frontiers of Entrepreneurship Research," Babson College, pp. 48-49

Groh, A. P. and H. Liechtenstein (2009a), "International Allocation Determinants of Institutional Investments in Venture Capital and Private Equity Limited Partnerships," IESE Business School Working Paper 726.

Groh, A. P. and H. Liechtenstein (2009b), "How Attractive is Central Eastern Europe for Risk Capital Investors?," Journal of International Money and Finance, forthcoming.

Hellmann, T. and M. Puri (2000), "The Interaction between Product Market and Financing Strategy: The Role of Venture Capital,” Review of Financial Studies, 13,4, pp. 959-984.

Jeng, L. A. and Ph. C. Wells (2000), "The Deteminants of Venture Capital Funding: Evidence across Countries," Journal of Corporate Finance, 6, pp. 241-289.

Johnson, S. H., J. McMillan, and C. M. Woodruff (1999), "Property Rights, Finance and Entrepreneurship," SSRN Working Paper 198409.

Kaplan, S. N. and A. Schoar (2005), "Private Equity Performance: Returns, Persistence, and Capital Flows," Journal of Finance, 60, pp. 1791-1823.

Karsai, J., M. Wright, Z. Dudzinski, and J. Morovic (1998), "Screening and Valuing Venture Capital Investments: Evidence from Hungary, Poland and Slovakia," Entrepreneurship \& Regional Development, 10, pp. 203-224.

Klonowski, D. (2005), "How Do Venture Capitalists Make Investment Decisions in Central and Eastern Europe?," Brandon University Working Paper.

Knack, S. and P. Keefer (1995), "Institutions and Economic Performance: Cross-country Tests Using Alternative Institutional Measures,” Economics and Politics, 7, pp. 207-228. 
Köke, F. J. (1999), "Institutional Investment in Central and Eastern Europe: Investment Criteria of Western Portfolio Managers,” ZEW Discussion Paper, pp. 99-37.

Kortum, S. and J. Lerner (2000), “Assessing the Contribution of Venture Capital to Innovation," Rand Journal Economics, 31,4, pp. 674-692.

La Porta, R., F. López-de-Silanes, A. Shleifer, and R. Vishny (1997), "Legal Determinants of External Finance," Journal of Finance, 52, pp. 1131-1150.

La Porta, R., F. López-de-Silanes, A. Shleifer, and R. Vishny (1998), "Law and Finance," Journal of Political Economy, 106, pp. 1113-1155.

La Porta, R.; F. López-de-Silanes, A. Shleifer, and R. Vishny (2002), "Investor Protection and Corporate Valuation," Journal of Finance, 57, pp. 1147-1170.

Lazear, E. P. (1990), “Job Security Provisions and Employment," Quarterly Journal of Economics, 105, pp. 699-726.

Lee, S. M. and S. J. Peterson (2000), "Culture, Entrepreneurial Orientation and Global Competitiveness," Journal of World Business, 35, pp. 401-416.

Lerner, J. and A. Schoar (2004), "The Illiquidity Puzzle: Theory and Evidence from Private Equity," Journal of Financial Economics, 72, pp. 3-40.

Lerner, J. and A. Schoar (2005. "Does Legal Enforcement Affect Financial Transactions? The Contractual Channel in Private Equity," Quarterly Journal of Economics, 120, pp. 223-246.

Levine, R. (1997), “Financial Development and Economic Growth: Views and Agenda," Journal of Economic Literature, 35, pp. 688-726.

Mauro, P. (1995), “Corruption and Growth,” Quarterly Journal of Economics, 110, pp. 681-712.

Megginson, W. (2004), “Toward a Global Model of Venture Capital?," Journal of Applied Corporate Finance, 16, pp. 89-107.

Michelacci, C. and J. Suarez (2004), "Business Creation and the Stock Market," Review of Economic Studies, 71, pp. 459-481.

Roe, M. (2006), “Political Determinants of Corporate Governance,” Oxford.

Romain, A. and B. van Pottelsberghe de la Potterie (2004), "The Determinants of Venture Capital: A Panel Analysis of 16 OECD Countries," Université Libre de Bruxelles, Working Paper WP-CEB 04/015.

Sapienza, H., S. Manigart, and W. Vermeir (1996), "Venture Capitalist Governance and Value Added in Four Countries," Journal of Business Venturing, 11, pp. 439-469.

Schertler, A. (2003), "Driving Forces of Venture Capital Investments in Europe: A Dynamic Panel Data Analysis, European Integration, Financial Systems and Corporate Performance," United Nations University (EIFC), Working Paper 03-27.

Svensson, J. (1998), "Investment, Property Rights and Political Instability: Theory and Evidence," European Economic Review, 42, pp. 1317-1341.

Wilken, P. H. (1979), “Entrepreneurship: A Comparative and Historical Study,” Norwood. 